\title{
ॠUSGS
}

science for a changing world

Prepared in cooperation with Colorado Parks and Wildlife

\section{Evaluation of the Raven sUAS to Detect and Monitor Greater Sage-Grouse Leks within the Middle Park Population}

By Leanne Hanson, Christopher L. Holmquist-Johnson, and Michelle L. Cowardin

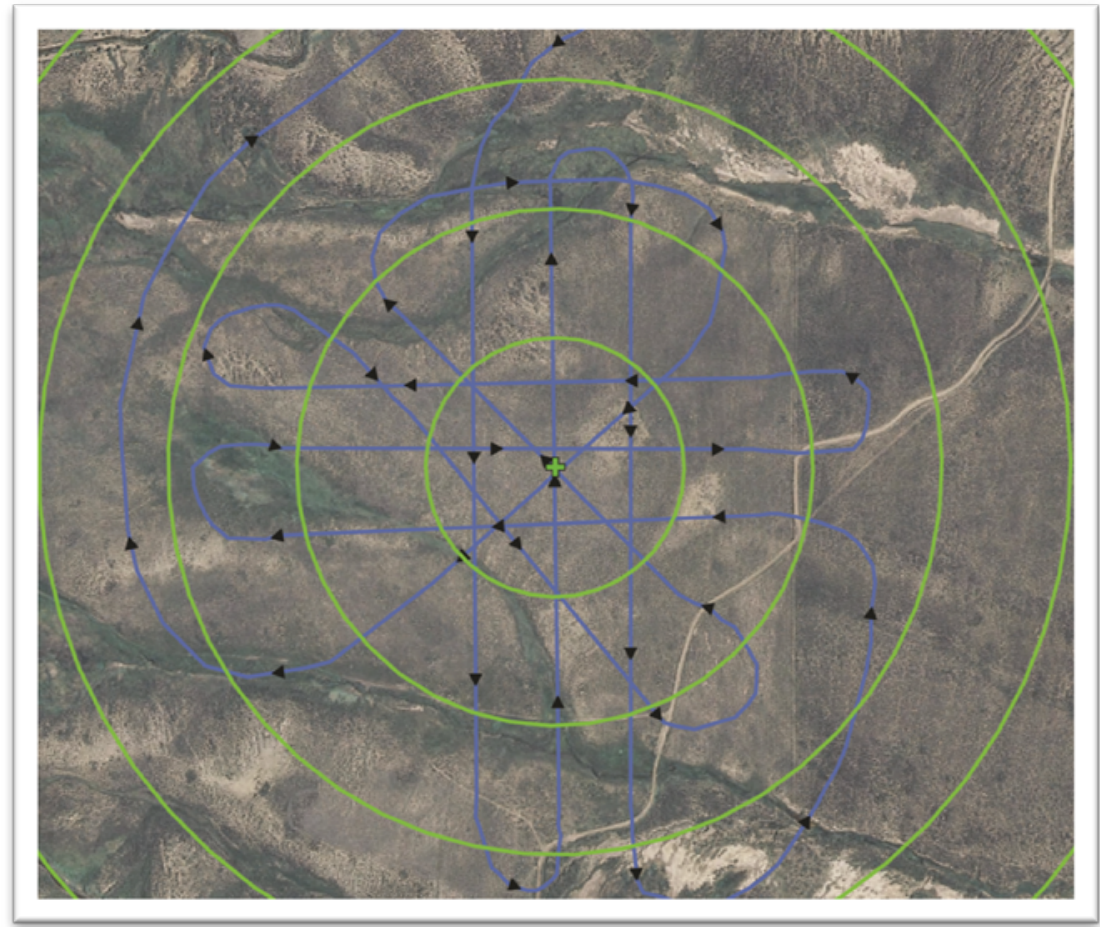

Open-File Report 2014-1205

U.S. Department of the Interior

U.S. Geological Survey 


\section{U.S. Department of the Interior \\ SALLY JEWELL, Secretary}

\section{U.S. Geological Survey \\ Suzette M. Kimball, Acting Director}

U.S. Geological Survey, Reston, Virginia: 2014

For more information on the USGS-the Federal source for science about the Earth, its natural and living resources, natural hazards, and the environment-visit http://www.usgs.gov or call 1-888-ASK-USGS (1-888-275-8747)

For an overview of USGS information products, including maps, imagery, and publications, visit http://www.usgs.gov/pubprod

To order this and other USGS information products, visit $h$ ttp://store.usgs.gov

Any use of trade, firm, or product names is for descriptive purposes only and does not imply endorsement by the U.S. Government.

Although this information product, for the most part, is in the public domain, it also may contain copyrighted materials as noted in the text. Permission to reproduce copyrighted items must be secured from the copyright owner.

Suggested citation:

Hanson, Leanne, Holmquist-Johnson, C.L., and Cowardin, M.L., 2014, Evaluation of the Raven sUAS to detect and monitor Greater Sage-Grouse leks within the Middle Park population: U.S. Geological Survey Open-File Report 2014-1205, 20 p., http://dx.doi/org/10.3133/ofr20141205.

ISSN 2331-1258 (online) 


\section{Contents}

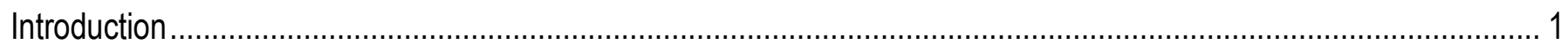

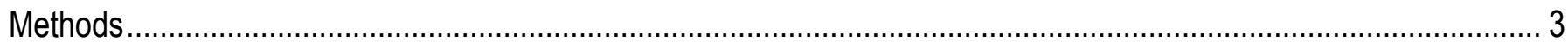

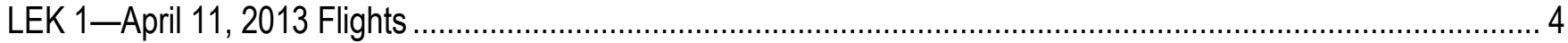

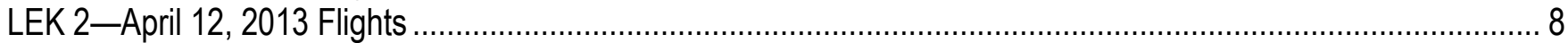

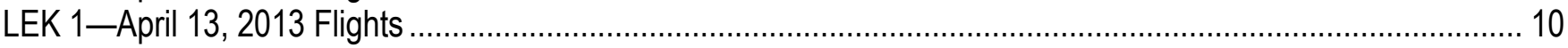

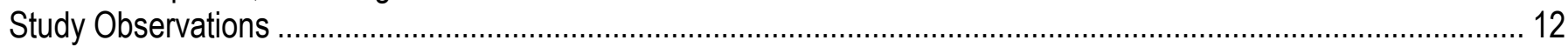

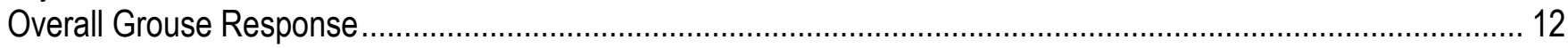

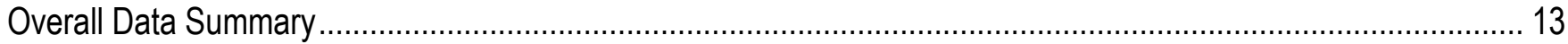

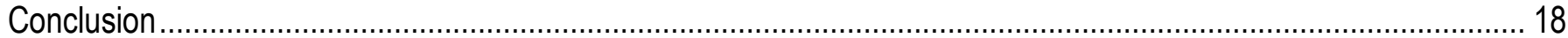

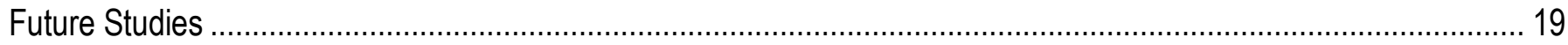

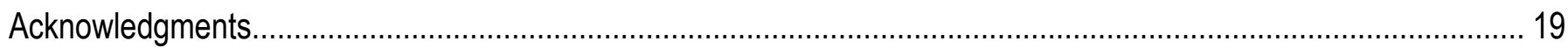

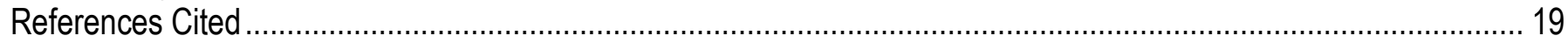

\section{Figures}

1. Lek 1, Flight 1: side-looking thermal infrared sensor in an EastWest flight path (transect) from the North to South using navigating waypoint mode 5

2. Lek 1, Flight 2: NADIR thermal infrared sensor in a flight path from all cardinal directions using altitude mode ........ 6

3. Lek 1, Flight 3: side-looking thermal infrared sensor in a circular flight path using loiter mode ................................. 7

4. Lek 2, Flight 6: side-looking thermal infrared sensor in a circular flight path using loiter mode ............................... 9

5. Lek 1, Flight 12: NADIR thermal infrared sensor in a North/South flight path (transect) from the East to West using navigating waypoint mode .................................................................................................. 11

6. Thermal infrared image of lek showing example of greater sage-grouse heat signature and identification .............. 14

7. Example image from GoPro Hero 3 camera showing greater sage-grouse on lek ........................................... 15

8. Example image from GoPro Hero 3 camera showing full field of view and zoomed-in section identifying greater sage-grouse on lek 16

9. Thermal infrared image showing example of heat signature and identification of greater sage-grouse (top) compared to cattle in adjacent pasture (bottom). 


\section{Conversion Factors}

\begin{tabular}{|c|c|c|}
\hline Multiply & By & To obtain \\
\hline \multicolumn{3}{|c|}{ Length } \\
\hline inch (in.) & 2.54 & centimeter $(\mathrm{cm})$ \\
\hline foot (ft) & 0.3048 & meter $(\mathrm{m})$ \\
\hline mile (mi) & 1.609 & kilometer (km) \\
\hline yard (yd) & 0.9144 & meter $(\mathrm{m})$ \\
\hline \multicolumn{3}{|c|}{ Area } \\
\hline acre & 4,047 & square meter $\left(\mathrm{m}^{2}\right)$ \\
\hline square foot $\left(\mathrm{ft}^{2}\right)$ & 929.0 & square centimeter $\left(\mathrm{cm}^{2}\right)$ \\
\hline square foot $\left(\mathrm{ft}^{2}\right)$ & 0.09290 & square meter $\left(\mathrm{m}^{2}\right)$ \\
\hline square inch $\left(\right.$ in $\left.^{2}\right)$ & 6.452 & square centimeter $\left(\mathrm{cm}^{2}\right)$ \\
\hline section (640 acres or 1 square mile) & 259.0 & square hectometer $\left(\mathrm{hm}^{2}\right)$ \\
\hline square mile $\left(\mathrm{mi}^{2}\right)$ & 259.0 & hectare (ha) \\
\hline square mile $\left(\mathrm{mi}^{2}\right)$ & 2.590 & square kilometer $\left(\mathrm{km}^{2}\right)$ \\
\hline \multicolumn{3}{|c|}{ Mass } \\
\hline ounce, avoirdupois (oz) & 28.35 & $\operatorname{gram}(\mathrm{g})$ \\
\hline pound, avoirdupois (lb) & 0.4536 & kilogram (kg) \\
\hline
\end{tabular}




\title{
Evaluation of the Raven sUAS to Detect and Monitor Greater Sage-Grouse Leks within the Middle Park Population
}

\author{
By Leanne Hanson, Christopher L. Holmquist-Johnson and Michelle L. Cowardin ${ }^{1}$
}

\section{Introduction}

Staff from the U.S. Geological Survey (USGS) Fort Collins Science Center and the Colorado Parks and Wildlife (CPW) Hot Sulphur Springs Office began discussions in 2011 for a proof of concept study to test the Raven RQ-11A small Unmanned Aircraft System (Raven sUAS) for its suitability to detect and monitor greater sage-grouse (Centrocercus urophasianus) (grouse) breeding sites (leks). During April 2013, the Raven sUAS was flown over two known lek sites within the Middle Park population in Grand County, Colorado. Known sites were flown to determine the reaction of the grouse to the aircraft and to determine if the technology had potential for future use of locating new leks and obtaining population counts on known, active lek sites.

The Raven sUAS is a hand-launched reconnaissance and data-gathering tool developed for the U.S. Department of Defense by AeroVironment, Inc. Originally designed to provide aerial observation, day or night, at line-of-site ranges up to 6.2 miles (mi) (10 kilometers [km]), the Raven sUAS has a wingspan of 4.5 feet (1.38 meters [m]) and weighs 4.2 pounds (1.9 [kg]). A 60-minute (min) lithium-ion rechargeable battery powers the system which also transmits live video (color or infrared imagery), compass headings, and location information to a ground control station. The Raven sUAS is typically operated by a three-person flight crew consisting of a pilot, mission operator, and a trained observer.

For this study, approval to fly the Raven sUAS in the U.S. national airspace required a Certificate of Authorization (COA) from the Federal Aviation Administration (FAA). The FAA COA review took two months and required approval from (1) the land owner and(or) manager of the areas over which flights were planned as well as (2) the USGS, Department of the Interior (DOI), U.S. Army, and the National Telecommunications and Information Administration (NTIA), which grants approval for the aircrafts radio communication frequency. This approval process takes a minimum of 45 days and is required because the Raven sUAS is a decommissioned military aircraft. Additionally, the FAA COA proposal package must contain information about the project, proposed flight operations, class of airspace, specific airframe description and capabilities, aircraft airworthiness certification, emergency procedures, flight crew qualifications, and any special-use permits relating to the project. Within the USGS, the COA package is reviewed by the USGS National UAS Project Office, the Bureau Aviation Manager, and the DOI Office of Aviation Services before the package is submitted to the FAA. The FAA-approved COA contains operating provisions specific to the flights, flight crew, safety, local and regional air traffic control centers notifications and flight reporting requirements. Several outreach

\footnotetext{
${ }^{1}$ Colorado Parks and Wildlife
} 
actions were planned to provide information and effectively communicate the project goals and design to the public and media. A press release was sent out two weeks prior to the flights announcing the project and a public meeting. The public meeting occurred the following week in the evening and included presentations by CPW and USGS. The CPW presented information about their greater sagegrouse management program history and this proof of concept study. The USGS made a presentation about the 2011 Sandhill crane (Grus canadensis) project which used sUAS flights to collect imagery and count cranes on their roosts at the Monte Vista National Wildlife Refuge. The Raven aircraft was on display along with several posters explaining other sUAS projects completed by the USGS. In addition, there was a media event during the week of the flights. The media event was scheduled after two days of flights so that information about the projects progress could be relayed to targeted media outlets. Due to species sensitivity, the lek locations and private landowners involved in the project were not disclosed.

Traditionally aerial wildlife counts and surveys have been conducted from manned, fixed-wing aircraft (Caughley, 1977) or helicopters and have been applied in research for a wide range of species (Sutherland, 2005) including sage-grouse (Connelly and others, 1981). These techniques tend to be expensive and can have safety, wildlife disturbance, and logistical concerns (Jones and others, 2006) but allow natural-resource managers to access areas that are difficult to reach as well as large expanses of habitat that are otherwise inaccessible (Quang and Lanctot, 1991). As early as 2001, Efroymson and others, 2001 called for the need "to provide guidance for the assessment of ecological risks from lowaltitude aircraft overflights" (p. 252). Although sUAS are being used more readily in many disciplines, their application for wildlife management has only recently been explored and has not been studied in depth (Sarda-Palomera and others, 2012). Watts and others (2012) identify the use of sUAS to survey large terrestrial animals and marine species and a potential to decrease disturbance to wildlife populations by conducting sUAS surveys (Watts and others 2010).

Studies have been completed assessing the impacts on avian species of traditional manned aerial overflights (Delaney and others, 1999). Military flight disturbance as a result of sonic booms has been studied (Anderson and others, 1989; Grubb and Bowerman, 1997; Stalmaster and Kaiser, 1997; Goudie and Jones, 2004), but these reports do not explore potential impacts on avian species from overflights with minimal noise. There have been studies looking at disturbance to raptor species (Anderson and others, 1989; Grubb and Bowerman, 1997; Stalmaster and Kaiser, 1997), seabirds (Brown, 1990; Harris, 2005), and waterfowl (Conomy and others 1998, Ward and others 1999, Goudie and Jones 2004) with reported disturbance effects differing among species and overflight patterns. From prior noise recording tests conducted by USGS with the Raven sUAS, not in association with this study, it was determined that noise decibels $(\mathrm{dB})$ peaked at $103.1 \mathrm{~dB}$ during the propeller check, and then decreased to $60-70 \mathrm{~dB}$ during flights at altitudes between 60 to 200 feet (ft) (18 to $61 \mathrm{~m}$ ) above ground level (AGL). These readings, however, did not distinguish wind from aircraft noise.

There have been very few studies completed on the use and effectiveness of sUAS to monitor and survey avian populations. All the studies found in the literature referenced research conducted on water and wading birds including Canada geese (Branta canadensis) and Snow geese (Chen caerulescens) (Chabot and Bird, 2012), Black-headed Gull (Chroicocephalus ridibundus) (SardaPalomera and others, 2012), and White Ibis (Eudocimus albus) and other wading birds (Jones and others, 2006). To our knowledge, there are no published reports or papers reporting the effects of unmanned aircraft surveys on greater sage-grouse or other upland gamebirds. Booth and others (2009) used a manned light sport airplane to conduct greater sage-grouse lek counts. Out of 14 approaches, grouse flushed from the lek on 12 approaches when the aircraft was flown within 200-300 m of the lek. Other grouse lek surveys using manned aerial flights (either airplanes or helicopters) for greater prairiechicken (Tympanuchus cupido) (Lehmann and Mauermann, 1963; Martin and Knopf, 1981) and lesser 
prairie-chicken (Tympanuchus pallidicinctus) (Schroeder and others, 1992), were able to successfully identify a lek site but were not always able to achieve an accurate grouse count compared to ground surveys.

Our study was designed to determine: (1) how will greater sage-grouse respond to sUAS overflights; (2) what are the optimal flight altitude, camera type, and camera position to detect and survey greater sage-grouse on leks; (3) with the optimal altitude, camera type and position, can males be distinguished from female greater sage-grouse; and (4) can we detect greater sage-grouse obscured by sagebrush.

\section{Methods}

The USGS and CPW staff monitored greater sage-grouse (grouse) reaction to the Raven sUAS flights and tested the Raven sensor's capability to detect and count grouse from April 10-13, 2013. These flights focused on two known Middle Park leks (Lek 1 and Lek 2). Test flights were conducted over known breeding sites beginning at civil twilight (approximately 30 min before sunrise) and continuing until the birds naturally started dispersing from the lek (approximately 8:00 am).

Originally, there were four leks selected to test the Raven sUAS; however, due to snow conditions that caused access difficulty, only two leks were flown. Lek 1 was on private lands and was flown on the morning of April 11, 2013 and April 13, 2013. Lek 2 was on Bureau of Land Management (BLM) lands and was flown only on the morning of April 12, 2013. The official names of the leks are not disclosed to protect the breeding site locations and to respect the privacy of individual landowners that granted access permission for the Raven sUAS flights. On the afternoon of April 10, 2013 (the day prior to the first scheduled flight), the USGS, BLM, and CPW staff along with the private land manager met to finalize the launch locations and logistics of the following days. The launch and observation locations were selected to provide an unobstructed line of sight to the lek while being far enough away from the lek to not disturb the birds during the set-up and operation of the aircraft.

The Raven sUAS video cameras are located in the nosecone and have fixed focal length, aperture, and depth of field settings. During flight, the aircraft altitude is used to change the camera's field of view (that is, $100 \mathrm{~m} \times 150 \mathrm{~m}$ vs. $200 \mathrm{~m} \times 300 \mathrm{~m}$ meters) and obtain sufficient pixel resolution to identify the item of interest (that is, sage grouse vs. cattle). As designed, the Raven sUAS has the option of using two types of onboard cameras and two camera positions. The camera types are a visible wavelength electro-optical (EO) or a thermal infrared (IR) video camera, and are either at a $45^{\circ}$ forwardlooking or $45^{\circ}$ side-looking position. In 2010, USGS staff modified a nosecone to allow for a straightdown (NADIR) view for the Raven sUAS IR camera. Imagery was collected over the grouse leks at various flight altitudes, using both camera types (EO and IR) and two of the camera positions (sidelooking and NADIR). Another Raven sUAS nosecone was modified in March 2013 to accommodate a GoPro Hero 3 Black Edition 12 megapixel camera which can capture either NADIR video or still images during flight. The Raven sUAS has two flight-control methods to navigate the plane, either manually or autonomously, and five modes of flight (manual, altitude, home, loiter, and navigating waypoints). In the manual flight-control method, the pilot controls the plane's flight path and altitude, while in the autonomous flight-control method, the plane is flown via pre-established mapped coordinates. Both flight-control methods and all five flight modes were used during data collection flights. For the thermal IR camera, the image can be displayed in white or black hot modes. This describes how the thermal signature is shown in the image as either white or black. Previous thermal IR flights showed that the white hot mode provided the best thermal detection capability for these types of flights and therefore all imagery was collected using the thermal IR cameras white hot mode. 
Each morning, prior to the flights the USGS Raven sUAS, pilots, observers, and support crew met at the predetermined sUAS operation and launch site 1 hour (hr) before the start of civil twilight to conduct an operational briefing (including safety, weather, and flight plan review) and to prepare for the flights. In addition, trained grouse observers were located at the lek to record and relay information to the operation center about the response and reaction of the grouse to the Raven sUAS flights and to collect a grouse count. Observers counted the number of male and female grouse at the lek before flights occurred and periodically throughout the flight duration.

\section{LEK 1-April 11, 2013 Flights}

On April 11, 2013, the USGS and CPW personnel met at the predetermined launch and operation location for Lek 1 to prepare for the flights. Two grouse observers were located in a blind at the lek site. A total of five flights were conducted on the morning of April 11, 2013. The initial flight was to determine the altitude needed to detect the grouse without disturbing the birds. The Raven sUAS was equipped with the side-looking IR camera and was flown at an altitude of $340 \mathrm{ft}$ (104 m) to $250 \mathrm{ft}$ (76 m) AGL. The objective of the first flight was to approach from the north flying transects towards the south. The start distance from the center of the lek was approximately $0.4 \mathrm{mi}(0.64 \mathrm{~km})$ with transects spaced every $0.1 \mathrm{mi}(0.16 \mathrm{~km}$; fig. 1$)$. The plane was flown using the autonomous flight control method by navigating waypoints that were used to create the flight path along the pre-determined $0.1 \mathrm{mi}$ transects described above. The total flight time for Flight 1 was approximately $18 \mathrm{~min}$ with a launch time of 6:14 am.

As the aircraft approached the lek from the north at an altitude of $250 \mathrm{ft}$ (76 m) AGL, the birds displayed no behavior change. At 10 min into Flight 1, project personnel decided to test a direct fly over of the lek in order to obtain the best possible imagery and to observe the birds' reaction.

For the second flight, the Raven sUAS was equipped with the NADIR IR camera and was flown at altitudes between $300 \mathrm{ft}(91 \mathrm{~m})$ and $200 \mathrm{ft}(61 \mathrm{~m})$ AGL. The objective of this flight was to fly directly over the lek at a lower flight altitude to determine the reaction of the grouse and test the capabilities of the NADIR IR camera. The plane was manually navigated in altitude mode and flown in all cardinal directions over the lek (fig. 2). The total flight time for Flight 2 was approximately 21 min with a launch time of $6: 41 \mathrm{am}$.

During the third test flight, the Raven sUAS was equipped with the side-looking IR camera and was autonomously navigated to the lek, then placed in loiter mode to circle the lek at a set distance. The flight altitude was set at $250 \mathrm{ft}(76 \mathrm{~m})$ AGL, and the plane continually circled at approximately $0.1 \mathrm{mi}$ $(0.16 \mathrm{~km})$ radius around the lek center (fig. 3). The white hot and black hot image display was tested during this flight, to ensure that previous postulations regarding white hot mode held true during project flight conditions (ambient air temperature, species of interest, altitude, etc.). The objective of this flight was to determine the capabilities of the loiter mode and to determine the reaction of the grouse as the Raven sUAS circled the displaying birds. The total flight time for Flight 3 was approximately $10 \mathrm{~min}$ with a launch time of 7:13 am. 


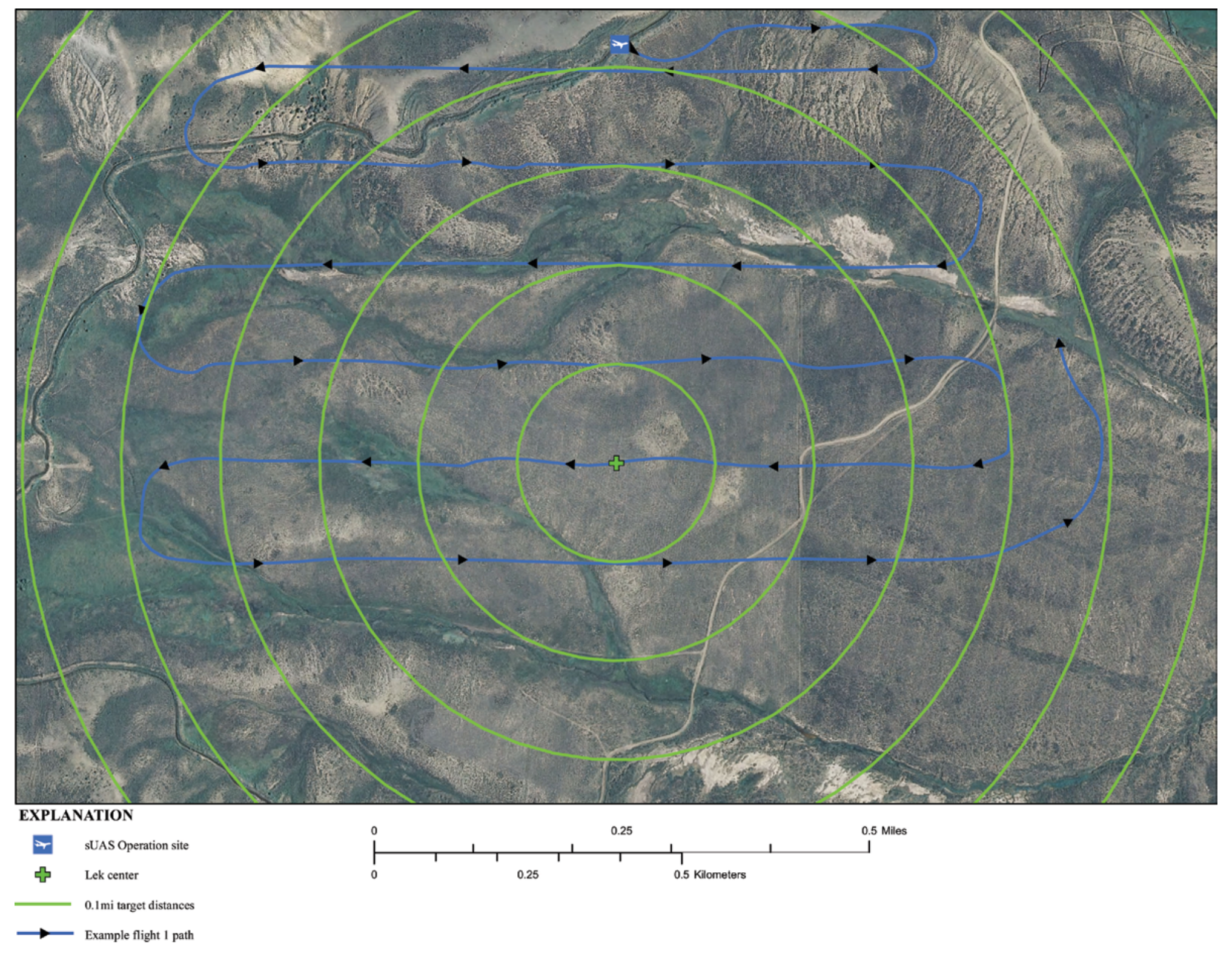

Figure 1. Lek 1, Flight 1: side-looking thermal infrared sensor in an east/west flight path (transect) from north to south using navigating waypoint mode. (sUAS, small Unmanned Aircraft System; mi, miles) 


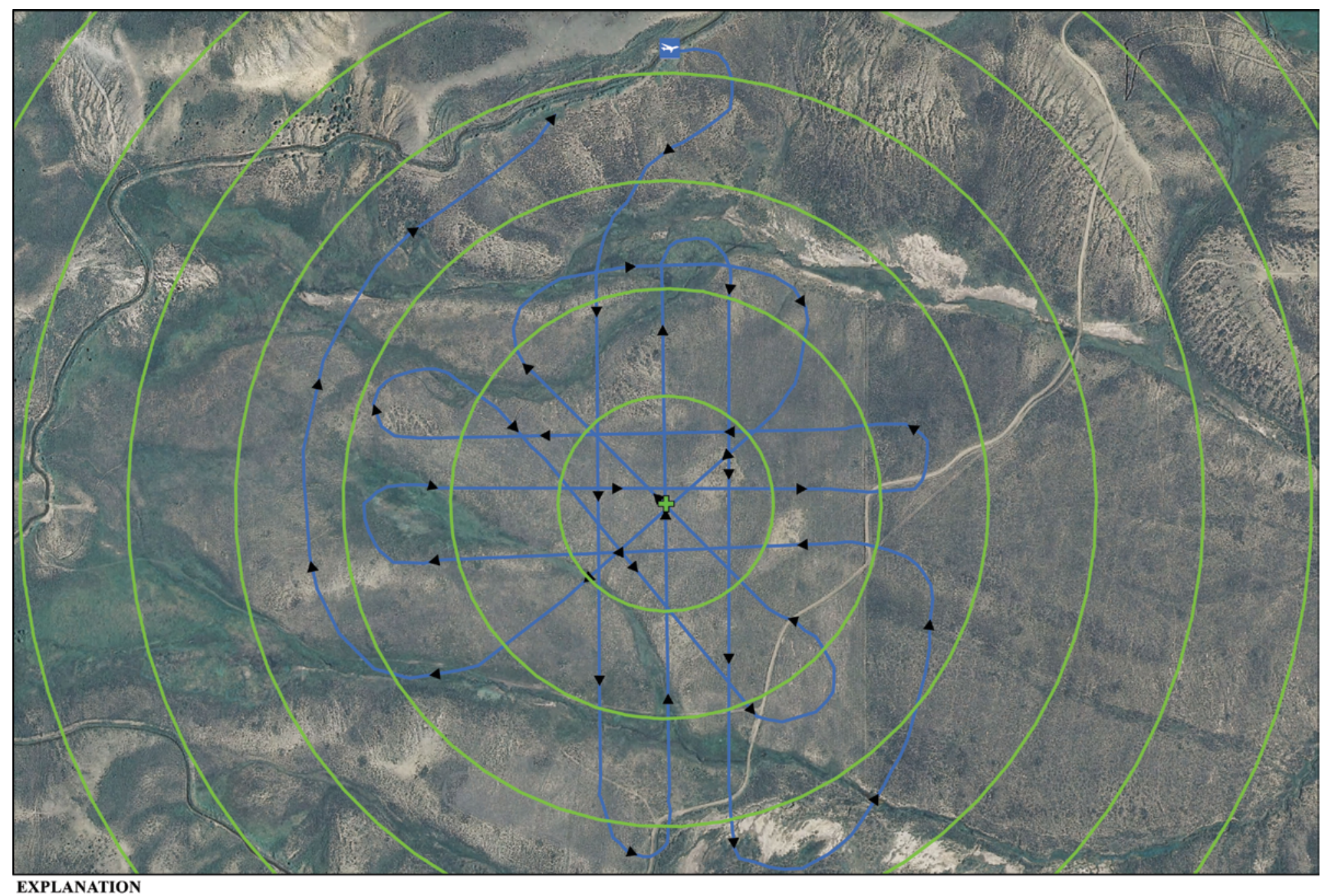

\section{EXPLANATION}

과 sUAS Operation site

\& Lek center

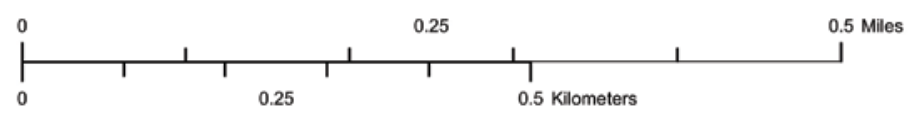

- $0.1 \mathrm{mi}$ target distances

$\longrightarrow$ Example flight 2 path

Figure 2. Lek 1, Flight 2: NADIR thermal infrared sensor in a flight path from all cardinal directions using altitude mode. (sUAS, small Unmanned Aircraft System; mi, miles) 


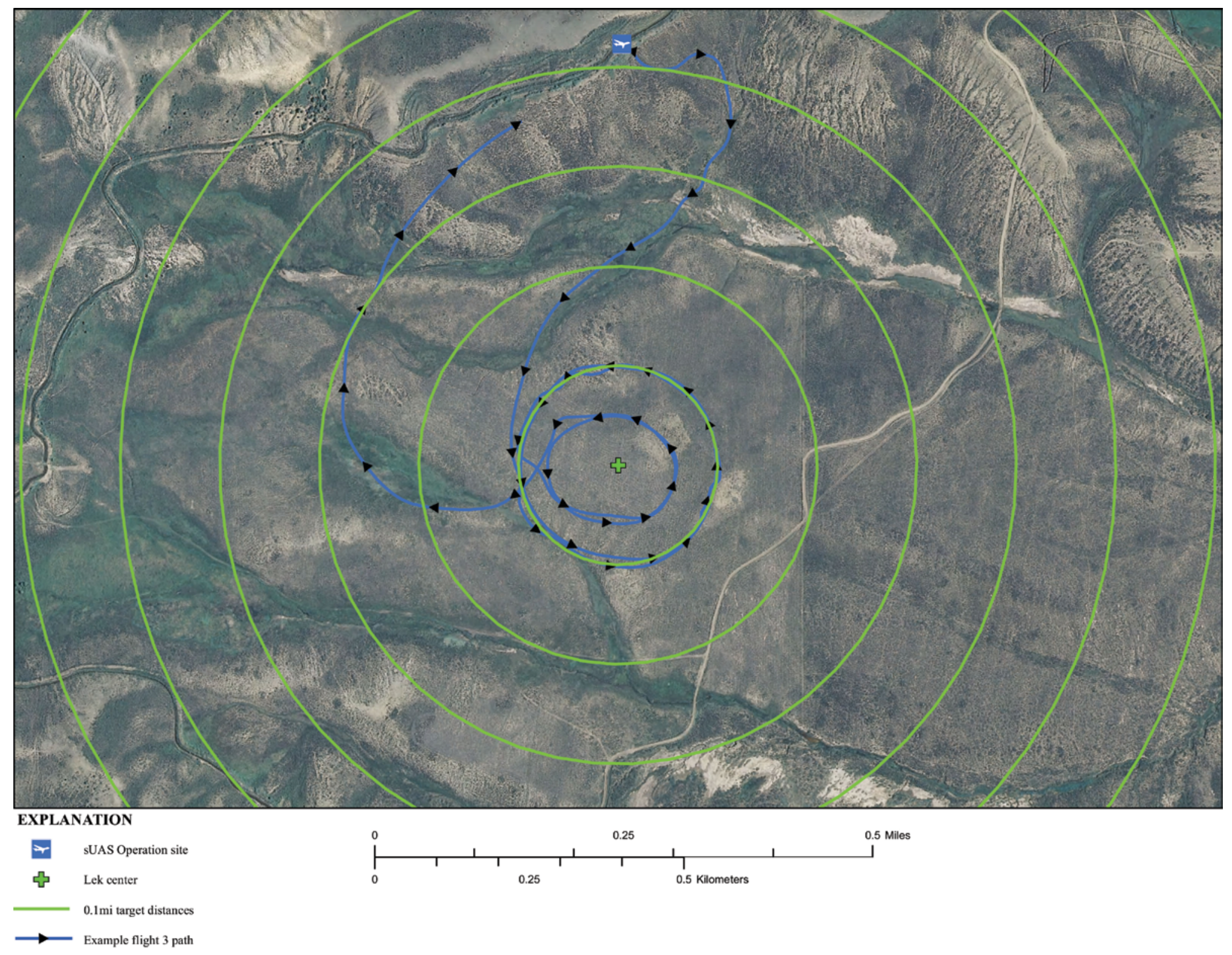

Figure 3. Lek 1, Flight 3: side-looking thermal infrared sensor in a circular flight path using loiter mode. (sUAS, small Unmanned Aircraft System; mi, miles) 
For the fourth and fifth test flights, the Raven sUAS was equipped with the NADIR GoPro Hero 3 camera using still frame capture mode every 2 seconds (sec). The flights were conducted in manual flight and autonomous flight control mode over the lek at an altitude between $130 \mathrm{ft}(40 \mathrm{~m})$ and $220 \mathrm{ft}$ $(67 \mathrm{~m})$ AGL. The objective of these flights was to determine the capabilities of the GoPro Hero 3 and the reaction of the grouse to a low altitude fly over. The total flight time for Flight 4 was approximately 17 min with a launch time of 7:33 am. The total flight time for Flight 5 was 10 min with a launch time of 8:15am. By the fifth flight, most of the grouse had dispersed from the lek or had stopped displaying.

\section{LEK 2-April 12, 2013 Flights}

On April 12, 2013, the USGS and CPW personnel met at the predetermined launch location near Lek 2 to prepare for the flights. One grouse observer was located in a vehicle at close proximity to the lek to observe and record the grouse response to the Raven sUAS flights. A total of four successful flights and two failed launches were conducted (Flights 6-11). The initial flight was to determine the response of the grouse to the Raven sUAS. Lek 2 has had recorded depredation by golden eagles (Aquila chrysaetos), so it was assumed that the grouse response to the Raven sUAS may differ from birds displaying on Lek 1. For Flight 6, the Raven sUAS was equipped with the side-looking IR camera and was manually flown in loiter mode around the lek at an altitude of approximately $200 \mathrm{ft}(61 \mathrm{~m})$ AGL, at a circling distance of $0.2 \mathrm{mi}(0.32 \mathrm{~km})$ from the lek center (fig. 4). The total flight time for Flight 6 was approximately $7 \mathrm{~min}$ with a launch time of 6:08 am. The flight was ended after 7 min to change the aircraft tail boom, which houses the down-link antenna, due to poor video transmission. 


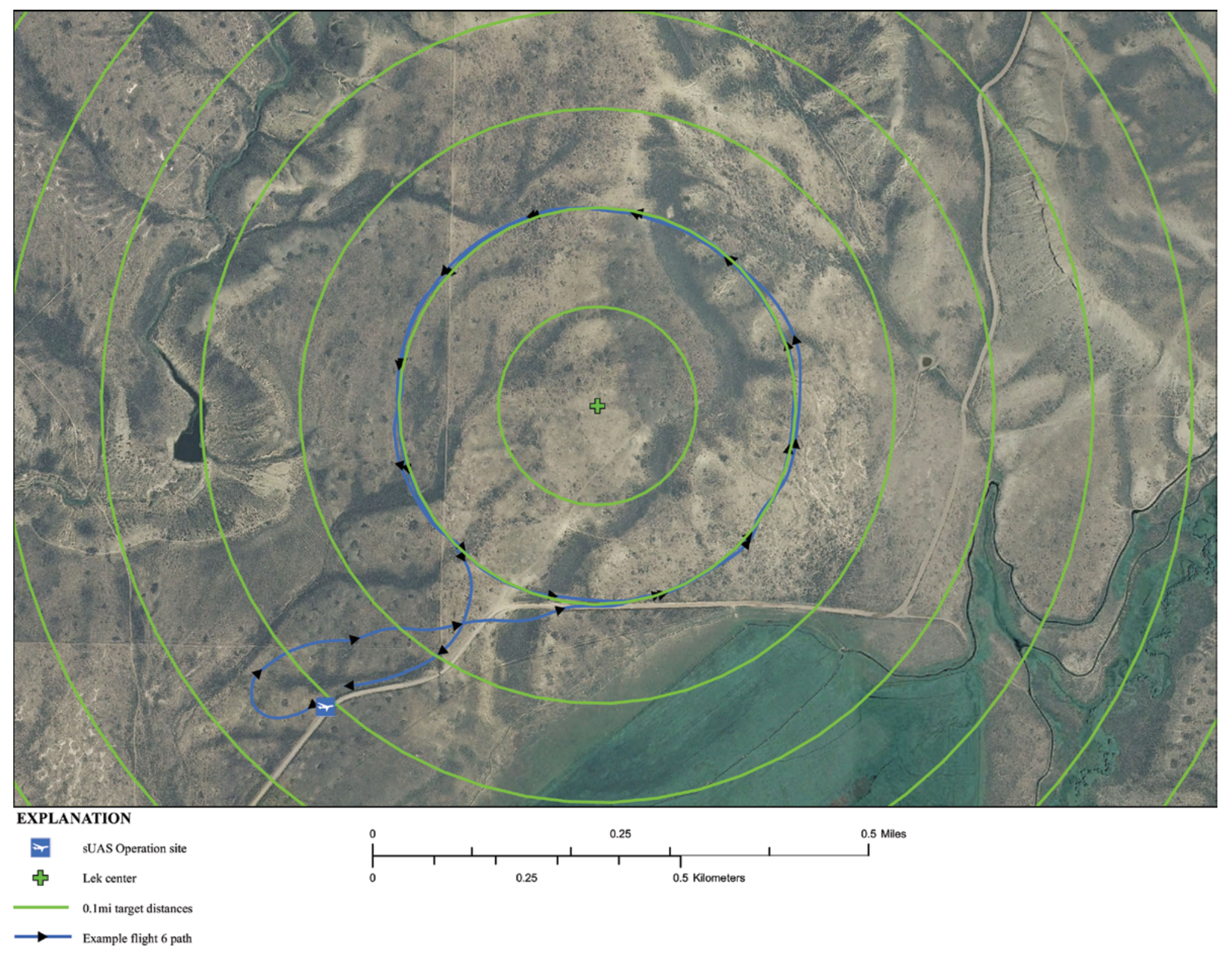

Figure 4. Lek 2, Flight 6: side-looking thermal infrared sensor in a circular flight path using loiter mode. (sUAS, small Unmanned Aircraft System; mi, miles) 
For Flight 7, the Raven sUAS was launched with a different tail boom and the side-looking IR camera. The aircraft was flown manually at $200 \mathrm{ft}(61 \mathrm{~m})$ AGL in loiter mode at $0.15 \mathrm{mi}(0.24 \mathrm{~km})$ from the lek center. The total flight time for Flight 7 was approximately 11 min with a launch time of 6:29 am. Flight 8 was also conducted manually using the side-looking IR in loiter mode at $200 \mathrm{ft}(61 \mathrm{~m})$ AGL at $0.1 \mathrm{mi}(0.16 \mathrm{~km})$ around the lek center. The total time for Flight 8 was $10 \mathrm{~min}$ with a launch time of 6:51. Flights 9 and 10 were failed launch attempts.

For Flight 11 the Raven sUAS was equipped with NADIR GoPro Hero 3 camera in video mode for $12 \mathrm{~min}$ and then changed to still frame capture mode every $2 \mathrm{sec}$ for the remainder of the flight. The GoPro Hero 3 was used to compare the camera quality and distortion level to the Raven sUAS stock IR camera. Flight 11 was manually flown at $200 \mathrm{ft}(61 \mathrm{~m})$ AGL at $0.1 \mathrm{mi}(0.16 \mathrm{~km})$ around the lek center in loiter mode. The total flight time was 22 min with a launch time of 7:31 am.

\section{LEK 1-April 13, 2013 Flights}

On April 13, 2013, the USGS and CPW personnel met at the predetermined launch and operation location to prepare for the second set of flights at Lek 1. Two grouse observers were located in a blind at the lek site to observe and record grouse response to the sUAS flights. A total of four flights (Flights 12-15) were conducted on the morning of April 13, 2013 at Lek 1. Since this was the second day of flights for Lek 1, project personnel determined to fly transects over the lek in an attempt to get an accurate count of total birds on the lek using the IR sensor and to obtain a count of displaying males from the GoPro Hero 3 imagery. A transect grid was established in a GIS layer prior to the flights, and the Raven sUAS was autonomously flown along the grid in navigating waypoint mode. Additional flights included loitering at different flight altitudes with the IR camera and collecting data to compare the GoPro Hero 2 and the GoPro Hero 3 camera imagery.

Flight 12 consisted of using the NADIR IR camera to fly 15 transects at $100-\mathrm{ft}(30-\mathrm{m})$ intervals starting $0.1 \mathrm{mi}(0.16 \mathrm{~km})$ from the lek center. Transects for Flight 12 were flown north to south and south to north for each transect starting along the eastern edge of the lek and moving westward (fig. 5). Transects within the $0.1 \mathrm{mi}(0.16 \mathrm{~km})$ radius around the lek were flown in both directions to account for the wind effect (tail wind vs. head wind) and potential differences in the thermal signature due to automatic gain adjustments made by the sensor. The Raven sUAS was flown at an altitude of approximately $200 \mathrm{ft}(61 \mathrm{~m})$ AGL. The total flight time for Flight 12 was approximately 37 min with a launch time of 6:17 am. 


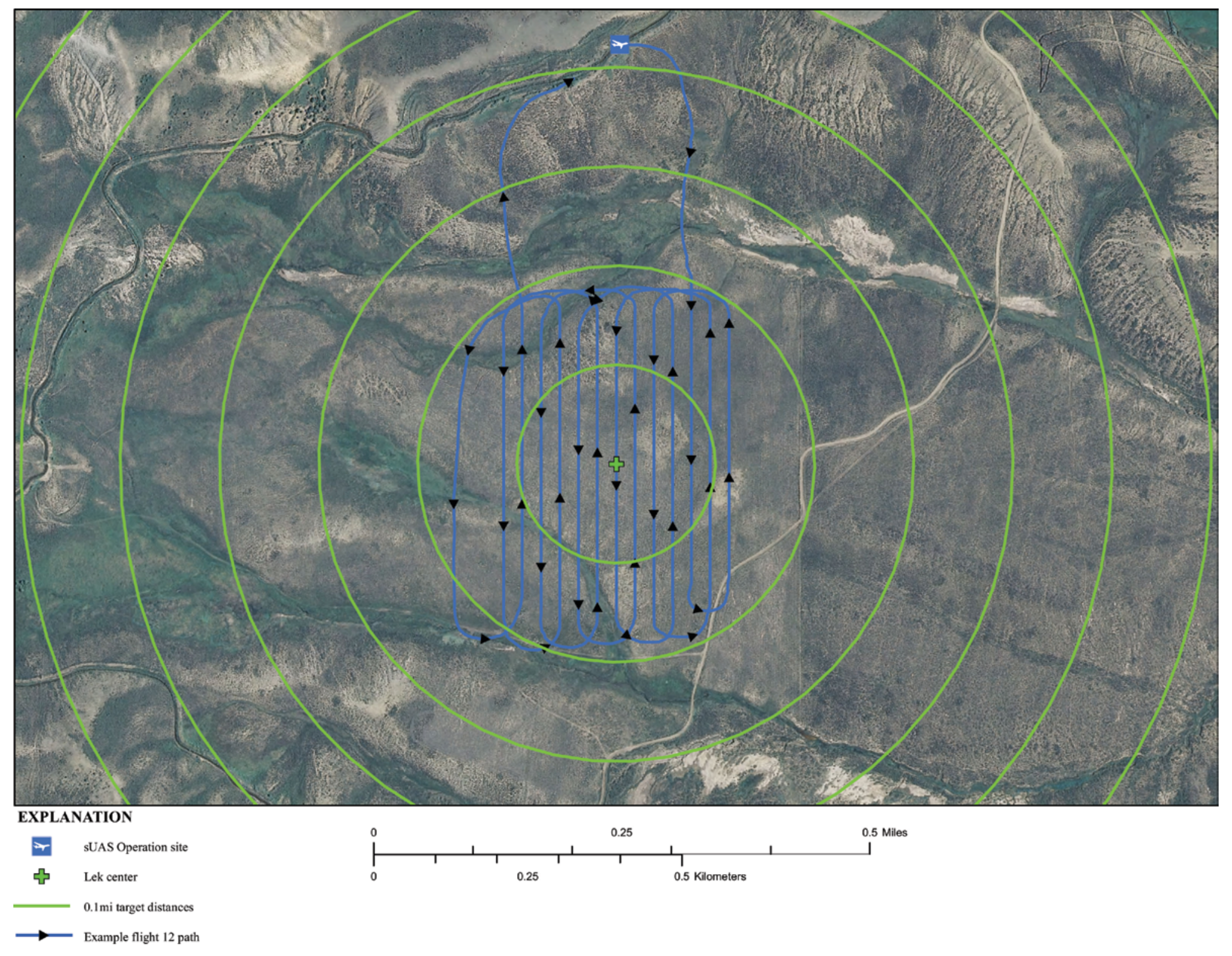

Figure 5. Lek 1, Flight 12: NADIR thermal infrared sensor in a north/south flight path (transect) from the east to west using navigating waypoint mode. (sUAS, small Unmanned Aircraft System; mi, miles) 
The Raven sUAS was equipped with the side-looking IR camera for Flight 13. The plane was autonomously flown in loiter mode at various elevations ranging from $200 \mathrm{ft}(61 \mathrm{~m})$ to $140 \mathrm{ft}(43 \mathrm{~m})$ AGL, with a start time of 7:05 am and a total flight time of $11 \mathrm{~min}$.

Flight 14 was similar to Flight 12, in that transects were flown to determine if a count of male and female grouse could be determined. For Flight 14, the Raven sUAS was equipped with the NADIR GoPro Hero 3 camera and both the video and still frame imagery was collected during three separate lek overflights. For the first and second overflights video imagery was collected along six transects spaced at 200-ft $(61-\mathrm{m})$ intervals at different flight altitudes. The first set of flights were flown north to south at approximately $200 \mathrm{ft}(61 \mathrm{~m})$ AGL. The second series of flights were flown south to north at approximately $120 \mathrm{ft}(37 \mathrm{~m})$ AGL. Still frame images were collected during a third overflight of five transects spaced at 250- $\mathrm{ft}(76-\mathrm{m})$ intervals at approximately $120 \mathrm{ft}(37 \mathrm{~m})$ AGL. Still frame images were collected every 1-2 sec during the third overflight during Flight 14. Flight 14 started at 7:28 am, with the total flight time being approximately 49 min.

The purpose of Flight 15 was to compare the image quality of the GoPro Hero 2, 5.44 millimeter $(\mathrm{mm})$ lens to the GoPro Hero 3, $2.8 \mathrm{~mm}$ lens. The flight start time was 8:37 am. By this time most of the grouse had moved off of the lek. Transects were flown north to south and south to north at a $250 \mathrm{ft}$ (76 m) spacing at $120 \mathrm{ft}(37 \mathrm{~m})$ and $130 \mathrm{ft}(40 \mathrm{~m})$ AGL. The total flight time was $29 \mathrm{~min}$.

\section{Study Observations}

\section{Overall Grouse Response}

Experienced grouse observers were stationed at the leks within close viewing distance of the displaying grouse during all three flight mornings. Two grouse observers were stationed in a blind at Lek 1 on April 11, 2013 and April 13, 2013 and one grouse observer was stationed in a vehicle at Lek 2 on April 12, 2013. The grouse observers arrived at the lek prior to civil twilight to not disturb the grouse. Grouse observers were instructed to record male and female sage-grouse numbers on the lek and to record any response behavior through the duration of the flights. The grouse observers were in radio communication with the operation center during the Raven sUAS flights. Flights did not begin until the grouse observers had sufficient light to obtain a reliable count of all grouse on the lek.

Greater sage-grouse response to the Raven sUAS flights was similar at both lek sites on all three mornings. There was no long-term response or reaction to the flights regardless of flight altitude or pattern, and no birds flushed from the leks. The grouse observers noted that, as the sUAS flew over the area, there was a loud buzzing noise, but that it was not obtrusive. As stated earlier, recorded decibel levels during Raven sUAS flights range between 60 to $70 \mathrm{~dB}$, which is equivalent to decibel readings for a normal conversation. Displaying males on the lek, however, reacted differently. Some males showed no reaction to the sUAS flights, while other males momentarily paused or crouched at times when the aircraft flew over or near the leks. If males showed any sign of disturbance by the Raven sUAS, they would only momentarily stop or slow their display, but never retracted their display feathers. Generally, the females also showed little to no response to sUAS flights. Females would crouch at times when the aircraft flew over but never flushed from the lek. Females continued to forage as the Raven sUAS flew over the lek. As the morning passed, the females started to walk off the lek and were eventually followed by some of the males. As late as 8:00 am on all three mornings, there were still displaying males on the leks.

The Raven sUAS flew over or near displaying greater sage-grouse on three separate mornings from approximately 6:20 am to 7:41 am, 6:10 am to 8:00 am, and 6:20 am to 8:00 am, on Leks 1, 2, and 1 , respectively. As the morning progressed, the grouse showed little to no response to the aircraft. On 
the morning of April 12, 2013, at Lek 2, during the second flight, the sUAS gained altitude towards the lek; the grouse observer noted that the noise of the sUAS was louder as it gained altitude and all the grouse stopped displaying. Within approximately $35 \mathrm{sec}$, the grouse started to display again, and showed no other reaction to the sUAS once it was at the flying altitude of $200 \mathrm{ft}(61 \mathrm{~m})$ AGL. Also, on April 13th, the sUAS went into a tight loiter around the lek at approximately 6:59 am; the female grouse seemed to respond by crouching down, but then resumed their normal behavior. Lek 2 is known to get predation pressure from golden eagles.

On April 11th, there were nine pronghorn antelope (Antilocapra americana) on Lek 1 and on the second morning there was a herd of cattle (cows and calves) in the adjacent pasture next to Lek 2. Neither the pronghorn antelope nor the cattle showed any reaction to nearby sUAS flights. No other wildlife or livestock were observed during the flights.

\section{Overall Data Summary}

Video captured during the $4.5 \mathrm{hr}$ of data-collection flights were compiled by date, lek, and flight number. The $80 \mathrm{~GB}$ of data were organized into folders, and each of the 15 flights were edited into flight videos to include only the footage collected over the leks. This included editing out pre-flight testing and travel to and from the launch site and lek. These videos were then viewed by project personnel who made notes regarding the flight time when birds were seen in the imagery and any additional interesting notes. Imagery collected with the thermal IR sensor was compared to the EO imagery collected with the GoPro Hero 3 camera, with project personnel taking notes of grouse, cattle, and antelope sightings recorded while watching. The grouse in the IR video appeared as white, undefined dots (as shown in fig. 6); as a result, we were not able to differentiate between males and females using the thermal IR camera. 


\section{NAUPA 13:20 04-11-13 4+C $7965 \mathrm{ft}$ MAG 192}

$22.9 \mathrm{~V}$

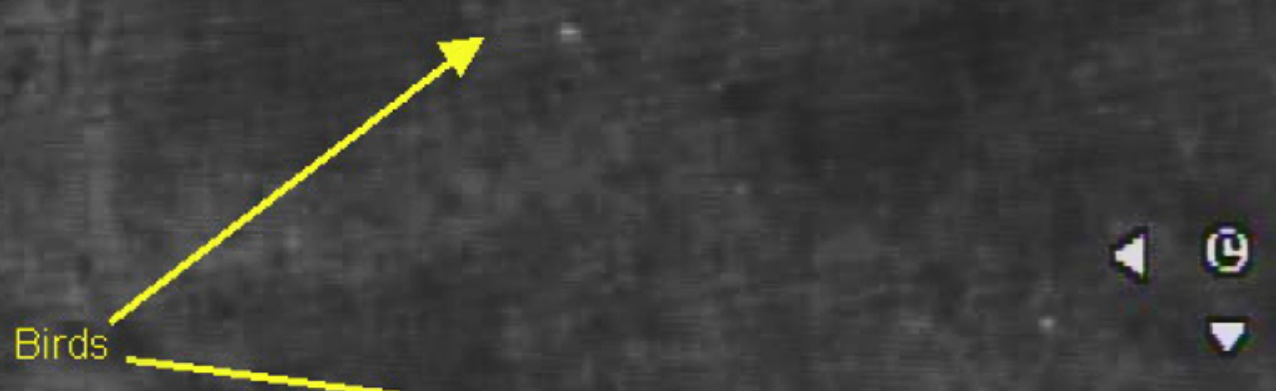

Figure 6. Thermal infrared image of lek showing example of greater sage-grouse heat signature and identification.

Male and female grouse could be identified in the visible, still images obtained with the GoPro Hero 3 camera mounted on the Raven sUAS (fig. 7). However, because of the scale of the photo, the reviewer must know where to look within the image to zoom in to identify the grouse (fig. 8). Because the birds appear too small to see in the full scale image, it would be extremely tedious to use the visible image to locate a new lek site. 


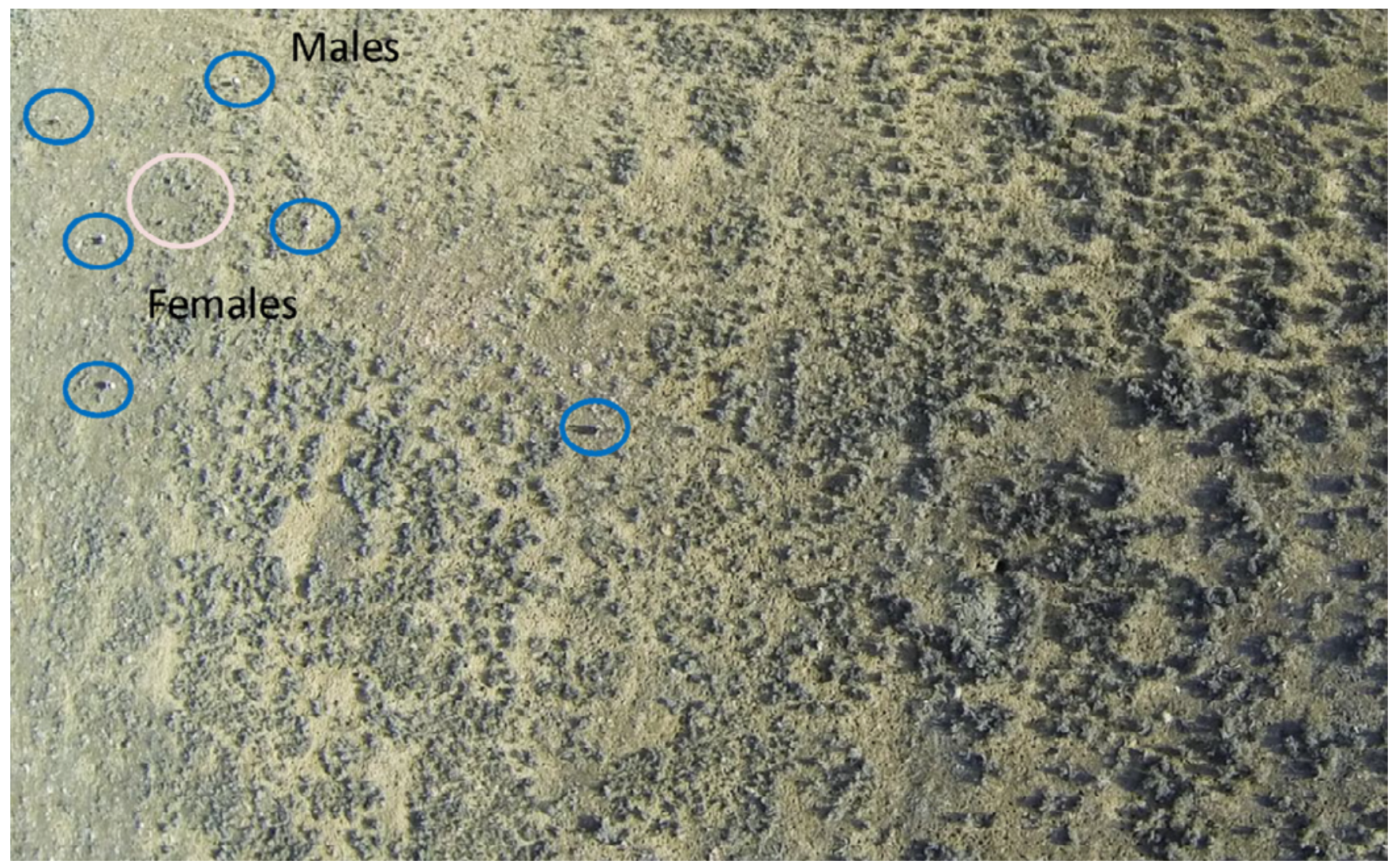

Figure 7. Example image from GoPro Hero 3 camera showing greater sage-grouse on lek. Blue circle $=$ male grouse, pink circle $=$ female grouse. 


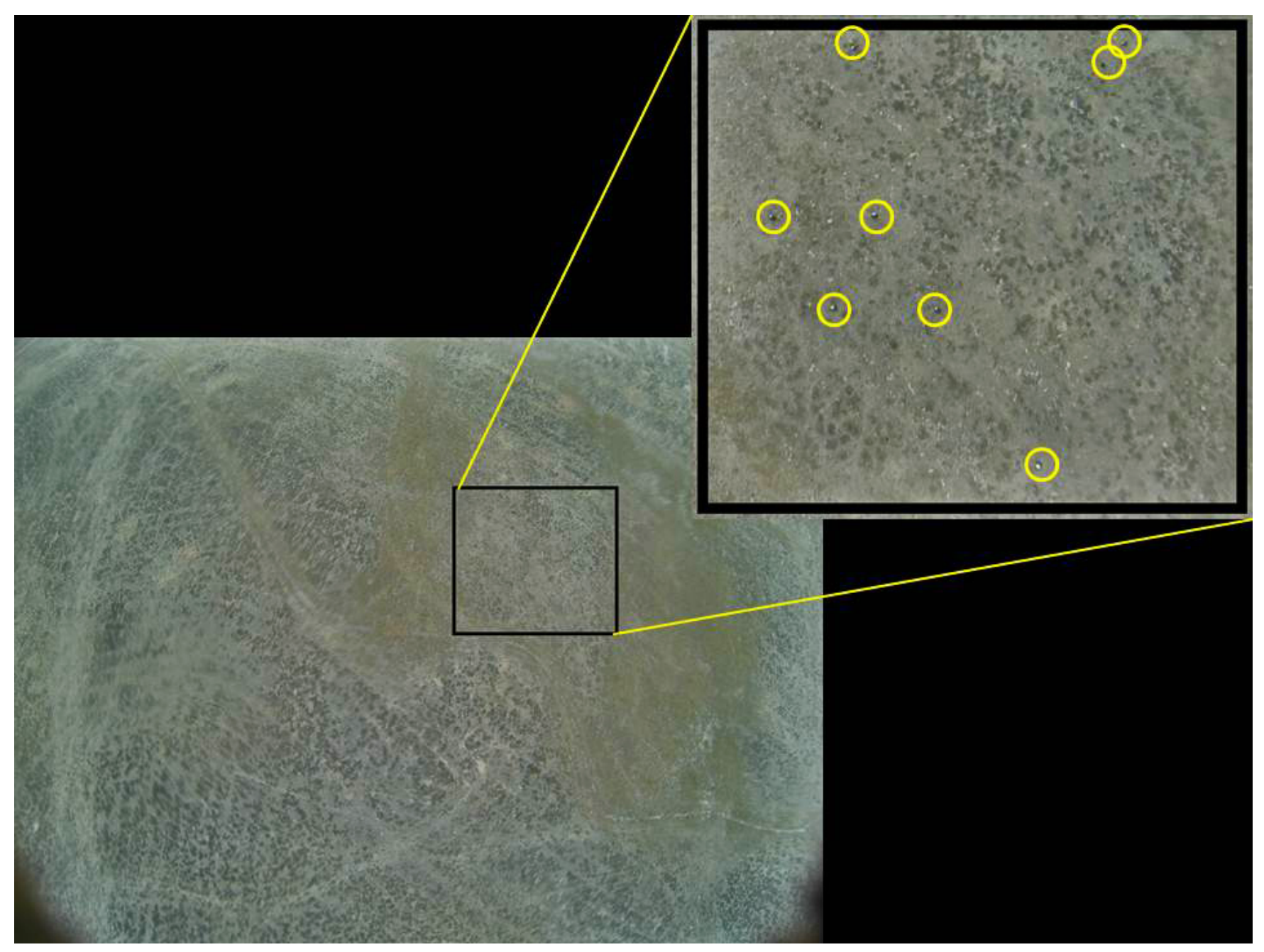

Figure 8. Example image from GoPro Hero 3 camera showing full field of view and zoomed-in section identifying greater sage-grouse on lek.

There were also some preliminary field observations that the thermal IR imagery was clearer when the Raven sUAS was traveling against the wind (that is, head wind) versus with the wind (that is, tail wind). These differences were associated with the sUAS travel speed over the lek. Traveling into the wind results in a slower ground speed of the aircraft, and therefore a clearer image is obtained. Travel with the wind results in a higher ground speed of the aircraft, causing image distortion.

While reviewing the imagery, personnel also noted the time and flight information when cattle appeared. As seen in figure 9, cattle have a different thermal signature when compared to thermal images showing greater sage-grouse. Cattle appear as larger and brighter white dots; the larger size and higher intensity of the white spots are because cattle have a larger body size than greater sage-grouse. 


\section{NAUDA $13: 20 \quad 04-11-13 \quad 4+C$ $7965 \mathrm{ft}$ \\ MAG 192 $22.9 \mathrm{~V}$ \\ $0.6 \mathrm{~km}$}
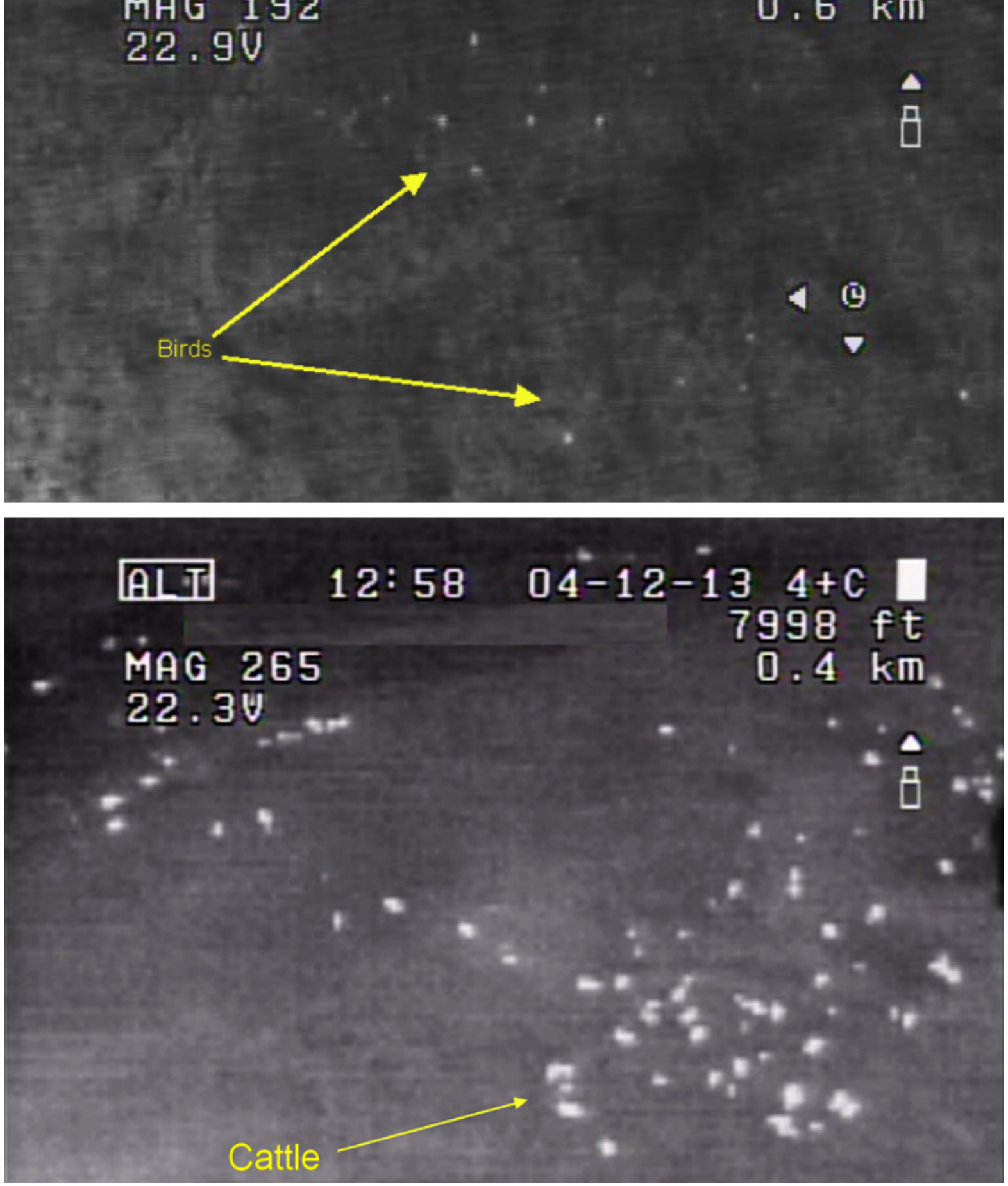

Figure 9. Thermal infrared image showing example of heat signature and identification of greater sage-grouse (top) compared to cattle in adjacent pasture (bottom). 
In future studies, it would be beneficial to develop a way to identify the grouse-observer blind and lek corners with a marker that can be seen by the sensors during data collection to aid in the orientation of the images during the image-review process. Also, transect spacing and loiter distance from leks need to be determined prior to the flights based on the flight altitude and lek size. This would allow for the images to be properly mosaicked and for the entire display area to be captured so accurate counts can be obtained from the images. The 100-ft $(30-\mathrm{m})$ transect used for Flight 12 did not have enough side overlap to successfully mosaic the images. The amount of overlap needed for these flights was difficult to determine prior to this project since the optimum flight altitude of image capture and grouse response were not known.

\section{Conclusion}

This project demonstrated that sUAS technology can be successfully used to detect greater sagegrouse at known lek locations. Both CPW and USGS staff involved were pleased with the project and the results. Greater sage-grouse experts consulted prior to the sUAS flights believed that the grouse would flush from the lek if the Raven sUAS was flown directly over the lek at an AGL of $400 \mathrm{ft}$ (122 $\mathrm{m})$ or less. This project demonstrated that greater sage-grouse may be more tolerant of overhead aerial disturbance than originally believed, when a battery-powered sUAS is used. sUAS overflights were conducted between $120 \mathrm{ft}(37 \mathrm{~m})$ to $300 \mathrm{ft}(91 \mathrm{~m})$ directly over the lek. The grouse observers at the leks noted that the noise from the Raven sUAS electric motor was minimal from the ground. We also determined that it was possible to identify grouse displaying on the lek with both the IR and visible cameras without flushing the grouse.

Considering the cameras used for the Raven sUAS greater sage-grouse lek overflights, data derived from the thermal IR camera may be more useful in detecting new lek locations, whereas the visible camera may be better suited to obtain count data at a known lek site. The current thermal IR sensor image quality is not suitable to distinguish male from female grouse; however, the IR sensor could be used during the spring breeding season to search areas and detect clusters of animals that could potentially be lekking grouse. Once these areas are identified, field crews could be sent to investigate and verify the presence or absence of lekking grouse. Additional tests should be conducted to determine the quality of the camera image for distinguishing between grouse and other animals with similar body size that may be encountered on the landscape. The IR sensor used during the Raven sUAS flights is an analog video sensor, and it is not capable of capturing a high enough quality image to be able to pause the video and obtain an accurate grouse count. Unlike the visible still images taken with a digital sensor, male and female grouse cannot be distinguished in the IR video. With a higher resolution IR image, it may be possible to pause the video to obtain a total count of birds present on the lek. The optimal flight altitude for the cameras used in this study was $200 \mathrm{ft}(61 \mathrm{~m})$ AGL. At this altitude the grouse were not disturbed and were detected by the cameras. At lower flight altitudes the Raven sUAS traveled too quickly over the lek area to obtain a reliable and clear image.

The Raven sUAS provides a non-intrusive safe and potentially effective method to locate new leks and obtain count estimates of breeding greater sage-grouse. Improving the onboard camera systems with accompanying georeferencing information will improve efficiencies of using the Raven sUAS for future wildlife population estimates. The use of sUAS to conduct wildlife surveys and searches is another tool to be utilized by wildlife managers. Although this technology has limitations in its range and flight duration (Watts and others, 2010), it can be useful for surveying large expanses of land and lands that are physically inaccessible. 


\section{Future Studies}

If funding is secured, the CPW and the USGS hope to conduct additional flights using improved thermal sensors, visible cameras, and a decibel meter. It would be desirable to conduct overflights at both Lek 1 and Lek 2 in 2014 using these upgraded sensor systems to compare the image quality. These flights would include data collection methods designed to test the ability to detect grouse hidden in sagebrush using the thermal IR sensor and determine the appropriate transect spacing needed to produce overlapping images that can be mosaicked and analyzed to obtain an accurate lek counts with both the IR and visible wavelength images. Using the decibel meter, we would collect data on the amount of noise measured at ground level from the aircraft during flights at various flight altitudes and throttle positions.

In addition, this technology could be used to search areas new lek sites. There are expansive tracts of lands where grouse are seen consistently during the breeding season, but an established lek has not been located. These areas cover large areas of rolling sagebrush habitat but are are difficult to physically access during the early spring season because of mud and snow conditions. Another opportunity to test the technology may be to conduct flights over Columbian sharp-tailed grouse (Tympanuchus phasianellus columbianus) leks. Columbian sharp-tailed grouse are smaller than sagegrouse, so it is unknown if they could be detected by the sUAS sensors.

\section{Acknowledgments}

The authors would like to thank the USGS National Unmanned Aircraft Systems Project Office for support with the communication frequency spectrum approval, the Federal Aviation Administration certificate of authorization approval, and providing J. Sloan as the trained observer during our flights. We also thank those that participated in the field aspect of the study, specifically C. Cesar, N. Bates, M. McGuire, and M. Kline, the anonymous private landowner who granted us permission to conduct the flights over their property and the ranch manager who assisted with the logistics of setting up the flights.

\section{References Cited}

Andersen, D.E., Rongstad, O.J., and Mytton, W.R., 1989, Response of resting redtailed hawks to helicopter overflights: The Condor, v. 91, p. 296-299.

Booth, D.T., Cox, S.E., Simonds, G.E., and Elmore B., 2009, Efficacy of two variations on an aerial lek-count method for greater sage-grouse: Western North American Naturalist, v. 69, p. 413-416. Brown, A.L., 1990, Measuring the effect of aircraft noise on sea birds: Environmental International, v. 16, p. 587-592.

Caughley, G., 1977, Sampling in aerial survey: Journal of Wildlife Management, v. 41, p. 605-615.

Chabot, D., and Bird D.M., 2012, Evaluation of an off-the-shelf unmanned aircraft system for surveying flocks of geese: Waterbirds, v. 35, p. 170-174.

Connelly, J.W., Arthur, W.J, and Markham, O.D., 1981, Sage grouse leks on recently disturbed sites: Journal of Range Management, v. 34, p. 153-154.

Conomy, J.T., Dubovsky, J.A., Collazo, J.A., and Fleming, W.J., 1998, Do black ducks and wood ducks habituate to aircraft disturbance?: Journal of Wildlife Management, v. 62, p. 1135-1142.

Delaney, D.K., Grubb, T.G., Beier, Paul, Pater, L.L., and Reiser, M.H., 1999, Effects of helicopter noise on Mexican spotted owls: Journal of Wildlife Management, v. 63, p. 60-76. 
Efroymson, R.A., Suter II, G.W., Rose, W.H., and Nemeth, S., 2001, Ecological risk assessment framework for low-altitude aircraft overflights-I. planning the analysis and estimating exposure: Risk Analysis, v. 21, p. 251-262.

Goudie, R.I., and Jones, I.L., 2004, Dose-response relationships of harlequin duck behaviour to noise from low-level military jet over-flights in central Labrador: Environmental Conservation, v. 31, p. 289-298.

Grubb, T.G., and Bowerman, W.W., 1997, Variations in breeding bald eagle responses to jets, light planes and helicopters: Journal of Raptor Research, v. 31, p. 213-222.

Harris, C.M., 2005, Aircraft operations near concentrations of birds in Antarctica-The development of practical guidelines: Biological Conservation, v. 125, p. 309-322.

Jones, G.P., Pearlstine, L.G., and Percival, H.F., 2006. An assessment of small unmanned aerial vehicles for wildlife research: Wildlife Society Bulletin, v. 34, p. 750-758.

Lehmann, V.W., and Mauermann, R.G., 1963, Status of Attwater's prairie chicken: Journal of Wildlife Management, v. 27, p. 713-725.

Martin, S.A., and Knopf, F.L., 1981, Aerial survey of greater prairie chicken leks: Wildlife Society Bulletin, v. 9, p. 219-221.

Quang, P.X., and Lanctot, R.B., 1991, A line transect model for aerial surveys: Biometrics, v. 47, p. 1089-1102.

Sarda-Palomera, Francesc, Bota, Gerard, Vinolo, Carlos, Pallares, Oriol, Sazatornil, Victor, Brotons, Lluis, Gomariz, Spartacus, and Sarda, Francesc, 2012, Fine-scale bird monitoring from light unmanned aircraft system: Ibis, v. 154, p. 177-183.

Schroeder, M.A., Giesen, K.M., and Braun, C.E., 1992, Use of helicopters for estimating numbers of greater and lesser prairie-chicken leks in eastern Colorado: Wildlife Society Bulletin 1992, p. 106113.

Stalmaster, M.V., and Kaiser, J.L., 1997, Flushing responses of wintering bald eagles to military activity: Journal of Wildlife Management, v. 61, p. 1307-1313.

Sutherland, W.J., 2005, Ecological census techniques-A handbook: Cambridge, U.K., Cambridge University Press.

Ward, D.H., Stehn, R.A., Erickson, W.P., and Derksen, D.V., 1999, Response of fallstaging brant and Canada geese to aircraft overflights in southwestern Alaska: Journal of Wildlife Management, v. 63, p. 373-381.

Watts, A.C., Perry, J.H., Smith, S.E., Burgess, M.A., Wilkinson, B.E., Szantoi, Zoltan, Ifju, P.G., and Percival, H.F., 2010, Small unmanned aircraft systems for low-altitude aerial surveys: Journal of Wildlife Management, v. 7, p. 1614-1619.

Watts, A.C., Ambrosia, V.G., and Hinkley, E.A., 2012, Unmanned aircraft systems in remote sensing and scientific research-Classification and considerations of use: Remote Sensing, v. 4, p. 16711692. 